\title{
Uneven malaria transmission in geographically distinct districts of Bobo- Dioulasso, Burkina Faso
}

Dieudonné Diloma Soma ${ }^{1,2^{*}}$, Daouda Kassié ${ }^{3,4,5}$, Seydou Sanou ${ }^{4}$, Fatou Biribama Karama ${ }^{4}$, Ali Ouari ${ }^{1}$, Wadaka Mamai ${ }^{6,7}$, Georges Anicet Ouédraogo ${ }^{2}$, Gérard Salem ${ }^{3,8}$, Roch Kounbobr Dabiré ${ }^{1}$ and Florence Fournet ${ }^{1,4^{*}}$

\begin{abstract}
Background: Urbanization is a main trend in developing countries and leads to health transition. Although non-communicable diseases are increasing in cities of low-income countries, vector-borne diseases such as malaria, are still present. In the case of malaria, transmission is lower than in rural areas, but is uneven and not well documented. In this study, we wanted to evaluate intra-urban malaria transmission in a West African country (Burkina Faso).
\end{abstract}

Methods: A cross-sectional study on 847 adults ( 35 to 59 year-old) and 881 children ( 6 months to 5 year-old) living in 1045 households of four districts (Dogona, Yeguere, Tounouma and Secteur 25) of Bobo-Dioulasso was performed between October and November 2013. The districts were selected according to a geographical approach that took into account the city heterogeneity. Malaria prevalence was evaluated using thick and thin blood smears. Human exposure to Anopheles bites was measured by assessing the level of IgG against the Anopheles gSG6-P1 salivary peptide. Adult mosquitoes were collected using CDC traps and indoor insecticide spraying in some houses of the four neighbourhoods. The Anopheles species and Plasmodium falciparum infection rate were determined using PCR assays.

Results: In this study, $98.5 \%$ of the malaria infections were due to Plasmodium falciparum. Malaria transmission occurred in the four districts. Malaria prevalence was higher in children than in adults (19.2 vs 4.4\%), and higher in the central districts than in the peripheral ones $(P=0.001)$. The median lgG level was more elevated in $P$. falciparuminfected than in non-infected individuals $(P<0.001)$. Anopheles arabiensis was the main vector identified $(83.2 \%$; 227 of the 273 tested mosquito specimens). Five $P$. falciparum-infected mosquitoes were caught, and they were all caught in the central district of Tounouma where 28.6\% (14/49) of the tested blood-fed mosquito specimens had a human blood meal.

Conclusions: This study showed that urban malaria transmission occurred in Bobo-Dioulasso, in all the four studied areas, but mainly in central districts. Environmental determinants primarily explain this situation, which calls for better urban management.

Keywords: Urbanization, Spatial heterogeneity, Malaria, Anopheles bites exposure, Burkina Faso

\footnotetext{
*Correspondence: dieusoma@yahoo.fr; florence.fournet@ird.fr

${ }^{1}$ Institut de Recherche en Sciences de la Santé/Centre Muraz, Bobo-Dioulasso

BP 545, Burkina Faso

Full list of author information is available at the end of the article
}

(c) The Author(s). 2018 Open Access This article is distributed under the terms of the Creative Commons Attribution 4.0 International License (http://creativecommons.org/licenses/by/4.0/), which permits unrestricted use, distribution, and reproduction in any medium, provided you give appropriate credit to the original author(s) and the source, provide a link to the Creative Commons license, and indicate if changes were made. The Creative Commons Public Domain Dedication waiver (http://creativecommons.org/publicdomain/zero/1.0/) applies to the data made available in this article, unless otherwise stated. 


\section{Background}

Vector-borne diseases continue to be a threat in most low-income countries, particularly malaria [1]. About 3.2 billion people, almost half of the world population, are at risk of malaria that caused an estimated 216 million cases and about 445000 deaths in 2016 [1]. Plasmodium falciparum is responsible for most (99\%) of these deaths [1] in Africa. Specifically, 90\% of malaria cases and 91\% of malaria deaths occurred in sub-Saharan Africa in 2016 [1]. In Burkina Faso, malaria represents the most common cause of medical consultation, with 7 million cases and 5,379 deaths in 2015 [1]. Moreover, due to the lack of good access to healthcare, the situation in the field may be more alarming.

Urbanization is accelerating in Africa, and demographic projections suggest that this phenomenon will further increase in the future [2]. It is generally thought that due to the higher concentration of healthcare facilities, urban populations enjoy better health than rural populations. Indeed, different studies showed that malaria transmission is lower in urban than in rural areas because of the unsuitability of urban environments for its vectors [3]. However, malaria epidemiology is different in urban contexts, and the delayed acquisition of a protective immunity causes more severe malaria [4]. Some studies have demonstrated that Anopheles vectors can adapt to the urban environment. For instance, urban agriculture offers great conditions for the development of anopheline larvae, as observed in small towns, such as Bouaké in Ivory Coast [5], but also in capital cities, such as Dakar in Senegal [6] and Antananarivo in Madagascar [7]. Human activities (for instance, brick making pits) also create breeding sites for Anopheles larvae [8, 9].

Moreover, urbanization is unequal in time and space, and also between continents, countries and within cities [10]. This urban heterogeneity could influence the effectiveness of health policies, particularly in the case of malaria, calling for a better assessment of local situations. The objectives of this study were to assess and compare the spatial patterns of malaria transmission within Bobo-Dioulasso (Burkina Faso) to optimize the environmental management and improve urban health.

\section{Methods}

\section{Study site and design}

Bobo-Dioulasso is the second largest city in Burkina Faso with an estimated population of 813,810 inhabitants in 2012 [11]. It is located in the southwestern part of the country $\left(11^{\circ} 10^{\prime} 7.31^{\prime \prime} \mathrm{N}, 4^{\circ} 17^{\prime} 52.24^{\prime \prime} \mathrm{W}\right)$. Malaria is present throughout the year with a peak of transmission during the rainy season, between May and October. Plasmodium species, mainly P. falciparum are transmitted by Anopheles gambiae s.s. [1, 12, 13].
The study was conducted in November 2013 in four districts: Dogona, Yeguere, Tounouma and Secteur 25 (Fig. 1). These districts were selected using a geographical approach that took into account the city heterogeneity [14]. This approach was based on the analysis of the built environment and the distribution of infrastructures, such as healthcare facilities and public fountains, using aerial photographs and satellite images. Tounouma is an old urbanized district in the central part of the town (Table 1). Dogona is located close to the city centre and has been more recently urbanized. These districts are crossed by the Houet River, a permanent river whose banks are heavily exploited by market gardening. Conversely, Secteur 25 is a peripheral, recently urbanized area that is still under construction and where healthcare facilities are scarce, different from Dogona and Tounouma. Yeguere is a peripheral, spontaneously formed district that completely lacks urban equipment. In Dogona and Tounouma, water is mainly provided by public fountains. In Secteur 25 individual connections are preferred.

The surveyed households were randomly selected on a cadastral map using the sampling tool of the ArcGis10 software. Distance from hydrographic network was calculated for each household and then for the district (Table 1). In each included household, one adult between 35 and 59 years of age and one child between 5 and 59 months of age were randomly selected. During household visits, information about their habits, particularly number of nets per household, date of acquisition, and use of mosquito net the night before the survey, was collected.

\section{Malaria parasite detection}

Blood samples were collected by finger pricking to prepare thick and thin blood smears. Axillary temperature was measured with an electronic thermometer after basic clinical examination. If the temperature was higher than $37.5{ }^{\circ} \mathrm{C}$, a malaria rapid diagnostic test (mRDT) was performed according to the manufacturer's instructions. People with a positive mRDT were immediately treated for free, as recommended by the National Malaria Control Programme of Burkina Faso.

Blood smears were fixed and stained with $10 \%$ Giemsa and examined at the Institut de Recherche en Sciences de la Santé (IRSS) in Bobo-Dioulasso to identify Plasmodium species. Plasmodium falciparum parasites (asexual stages) were counted in 200 leukocytes and parasite density was calculated for a fixed leukocyte count of 8000 cells/ $\mu$ l of blood. All thick and thin blood smears were read independently by two skilled technicians. Comparison of their results indicated that the estimated rates of parasite detection and parasite density did not differ significantly between technicians. Quality 


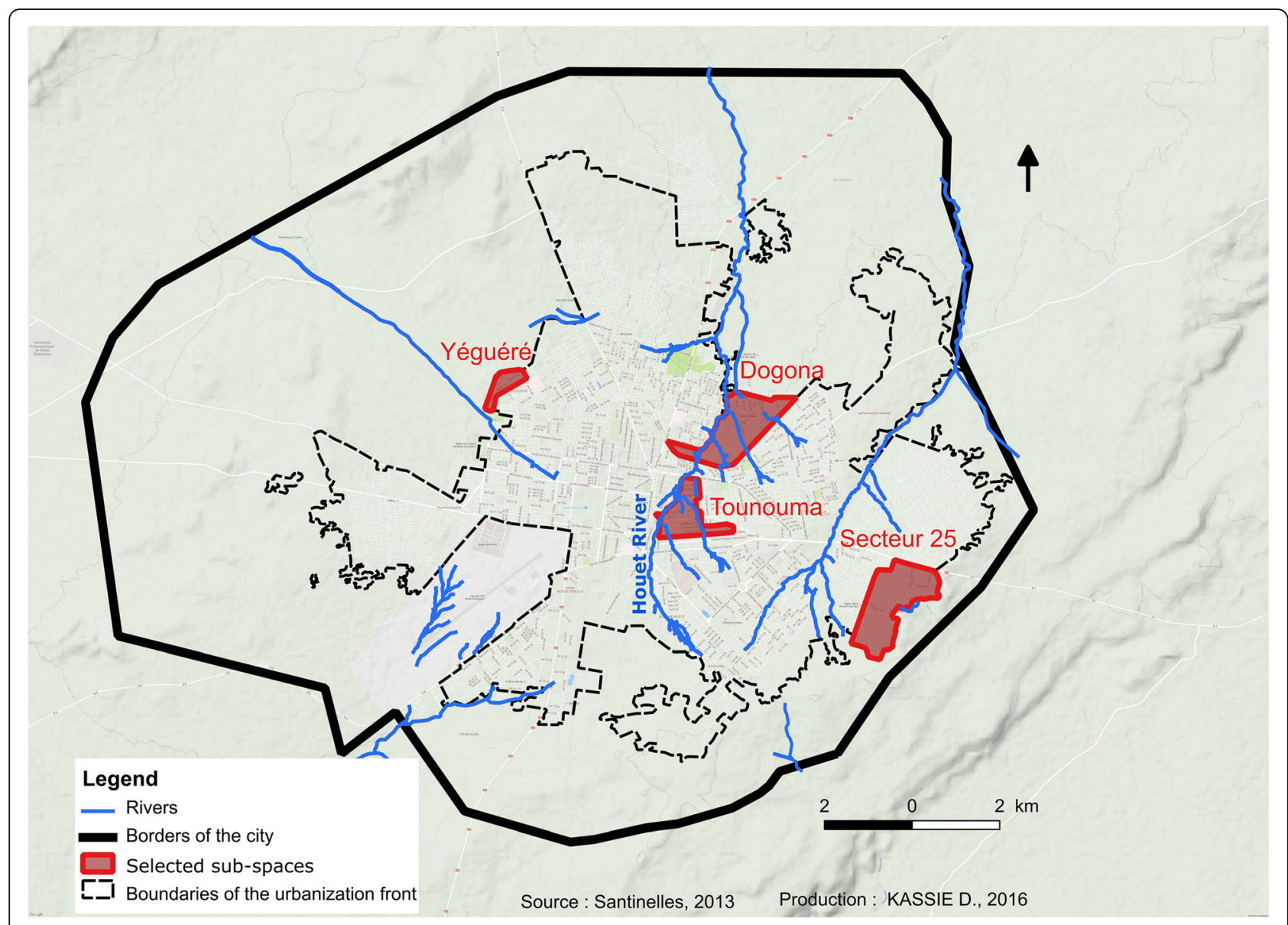

Fig. 1 Localization of the four districts and hydrographic network

control was regularly performed on randomly selected samples, representing $10 \%$ of all thick smears. A malaria case was defined as the presence of fever or history of fever during the past $48 \mathrm{~h}$ and parasitaemia $>0$.

\section{Exposure to Anopheles bites}

Blood samples for assessing mosquito bite exposure were collected on filter paper (Whatman ${ }^{\text {TM }} 3 \mathrm{MM}$ Chr, Paris, France). They were stored at $4{ }^{\circ} \mathrm{C}$ until use. The IgG response to the gSG6-P1 salivary peptide, which is specific for An. gambiae, was evaluated using enzyme-linked immunosorbent assay (ELISA), as previously described
$[15,16]$. Optical density (OD) was measured according to the protocol described by Poinsignon et al. [15]. The IgG response to the gSG6-P1 peptide was expressed as the $\Delta \mathrm{OD}$ value, as described by Sagna et al. [17]. The average specific immune response threshold of non-Anopheles exposed individuals ( $\triangle$ ODneg) was: $\triangle$ ODneg \pm 3 standard deviations $=0.204$. An individual was considered to be an immune responder when $\Delta \mathrm{OD}>0.204$.

\section{Entomological survey}

Mosquito collections were carried out inside and just outside four houses in each of the four districts using

Table 1 Presentation of the four districts according to the urbanization, position in the city, access to water supply and health care

\begin{tabular}{llllll}
\hline Districts & Age of district (years) & Location & Water supply & Access to health care & $\begin{array}{l}\text { Distance from hydrographic } \\
\text { network }^{\text {a }}(\mathrm{m})\end{array}$ \\
\hline Yeguere & 26 & Peripheral & None & Bad & 815 \\
Secteur 25 & 17 & Peripheral & Individual & Scarce & 597 \\
Tounouma & $>55$ & Central & Public fountain & Good & 152 \\
Dogona & 51 & Central & Public fountain & Good & 168 \\
\hline
\end{tabular}

${ }^{\mathrm{a}}$ Average distance between households surveyed and hydropgraphic network 
Table 2 Characteristics of malaria in the different districts of Bobo-Dioulasso, 2013

\begin{tabular}{|c|c|c|c|c|c|c|c|c|c|c|c|}
\hline \multirow[t]{2}{*}{ District } & \multirow[t]{2}{*}{ Households } & \multicolumn{5}{|c|}{ Children } & \multicolumn{5}{|c|}{ Adults } \\
\hline & & $\bar{n}$ & Malaria cases & $\%$ & $95 \% \mathrm{Cl}$ & $\overline{\text { Average parasitemia/ } / \mathrm{l}^{\mathrm{a}}}$ & $\bar{n}$ & Malaria cases & $\%$ & $95 \% \mathrm{Cl}$ & Average parasitemia/ $/\left.\right|^{\mid}$ \\
\hline Yeguere & 234 & 208 & 36 & 17.3 & $9.9-21.1$ & 4869 & 199 & 5 & 2.5 & $0-4.1$ & 118 \\
\hline Secteur 25 & 290 & 223 & 34 & 15.2 & $8.2-18.8$ & 1584 & 215 & 7 & 3.3 & $0-5.1$ & 68 \\
\hline Tounouma & 286 & 248 & 46 & 18.5 & $10.9-22.4$ & 4346 & 240 & 13 & 5.4 & $1.0-7.7$ & 546 \\
\hline Dogona & 235 & 202 & 53 & 26.2 & $17.6-30.6$ & 4782 & 193 & 12 & 6.2 & $1.5-8.6$ & 310 \\
\hline All districts & 1045 & 881 & 169 & 19.2 & $11.5-23.1$ & 3872 & 847 & 37 & 4.4 & $0.4-6.5$ & 275 \\
\hline
\end{tabular}

${ }^{\mathrm{a}}$ Among individuals with detectable parasitemia Abbreviation: $\mathrm{Cl}$, confidence interval

CDC traps during two consecutive nights (between 20:00 and 06:00 h). Indoor resting females were caught by spraying four other houses close to the CDC-sampling houses with insecticide aerosols between 06:00 and 09:00 $\mathrm{h}$ during the same two consecutive days. Dead or knockeddown mosquitoes were collected on white sheets laid down on the floor of the sprayed houses. Species identification was performed for An. gambiae complex specimens using the PCR method described by Santolamazza et al. [18]. Their infection rate was evaluated by PCR amplification as described by Morlais et al. [19]. The blood meal origin was determined by ELISA in blood-fed females [20] using antibodies against human and most frequently found animals in the study sites: cattle, sheep, dogs, donkeys and pigs.

\section{Statistical analysis}

The number of households to be surveyed and then the number of participants were calculated in order to observe significant differences between the four districts at the $5 \%$ threshold with a precision of $2.6 \%$, based on a prevalence of $5 \%$ (the smallest expected prevalence for malaria in adults). Malaria prevalence was calculated as the number of malaria cases reported to the population considered (children, adults). Malaria prevalence in the four districts as well as in the central and peripheral areas was compared by a Chi-square test. Parasitemia was calculated among those that had a detectable parasitemia. Variance analysis allowed the comparison between districts. The immunological assays were performed on a sub-sample $(n=273)$ of children and adults randomly selected from the whole sample. Normality distribution was tested using the Kolmogorov-Smirnov and Shapiro-Wilk tests. The non-parametric Mann-Whitney test was used to compare IgG Ab levels between independent groups, and the Kruskal-Wallis test for comparisons of more than two groups. IgG antibody levels between districts were analyzed using analysis of variance (ANOVA) with Tukey's honestly significant difference (HSD) post-hoc tests. A Pvalue $<0.05$ was considered as significant. Graph Pad Prism 5.0 Software and Microsoft Excel 2013 (Microsoft ${ }^{\odot}$, New York, USA) were used to produce graphics and perform statistical analyses.

\section{Results}

\section{Prevalence of malaria infection}

This study included 1728 individuals (847 adults and 881 children) living in 1045 households (Table 2). Longlasting insecticidal nets (LLIN) were distributed in July 2013 during the national campaign, just before the survey during which $97.6 \%$ of adults and $91 \%$ of children declared to have slept under their LLIN the night before.

A total of 206 cases of malaria were reported (Table 2). The prevalence of malaria infection was $12 \%(206 / 1728)$ in the whole population and was higher in children (19.2\%, 169/881; 95\% CI: 11.5-23.1\%) than in adults (4.4\%, 37/847; 95\% CI: 1.5-8.6\%) (Table 2). More malaria cases were observed in Dogona $(65 / 206)$ and Tounouna (59/206). In Secteur 25 and Yeguere 41 malaria cases were registered in each district. Comparative analyses that took into account the intra-urban distribution showed that malaria prevalence in children was significantly different in the four districts $(P=0.026)$. No difference in malaria prevalence distribution among districts was observed in adults. Comparing neighborhoods to two showed that Dogona was significantly different from Secteur 25 and Yeguere, but quite similar to Tounouma (Table 3). Comparison of the malaria prevalence for the

Table 3 Pairwise comparisons of the districts (probability after Chi-square test)

\begin{tabular}{|c|c|c|c|c|c|c|}
\hline & \multicolumn{2}{|l|}{ Secteur 25} & \multicolumn{2}{|l|}{ Tounouma } & \multicolumn{2}{|l|}{ Dogona } \\
\hline & Chi-square & $P$-value & Chi-square & $P$-value & Chi-square & $P$-value \\
\hline Yeguere & 0.336 & 0.562 & 0.118 & 0.731 & 4.808 & 0.028 \\
\hline Secteur 25 & - & - & 0.908 & 0.223 & 7.864 & 0.004 \\
\hline Tounouma & - & - & - & - & 3.835 & 0.048 \\
\hline Dogona & - & - & - & - & - & - \\
\hline
\end{tabular}




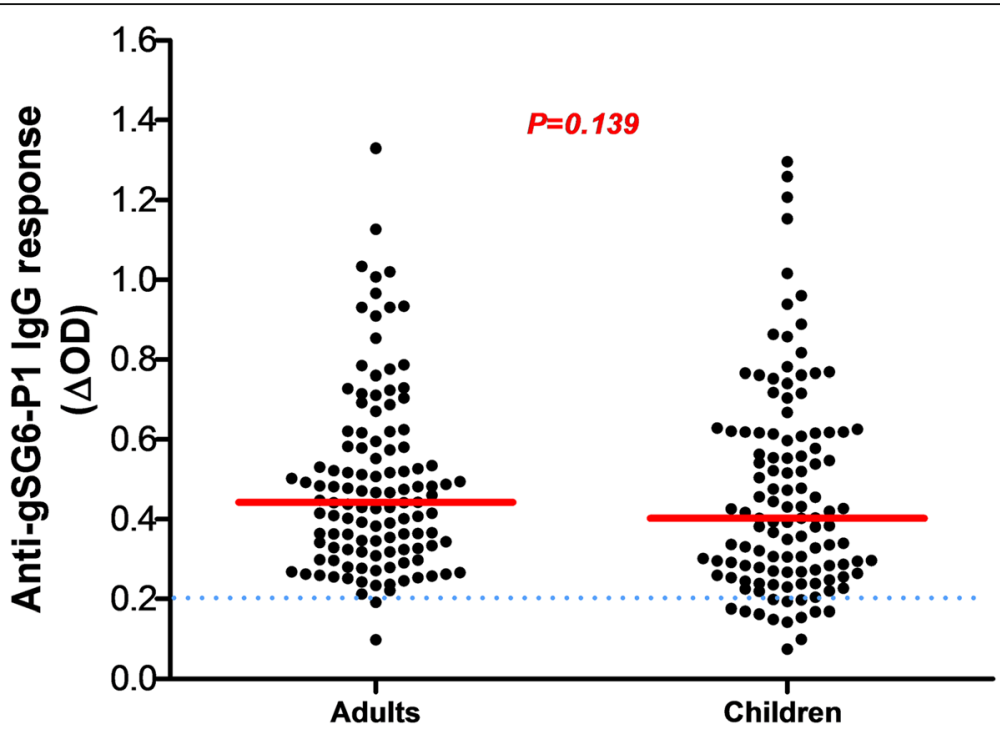

Fig. 2 Anti-gSG6-P1 lgG level in the four districts. Red bars indicate the median value in each group and the horizontal blue dotted line represents the cut-off for immune responders $(\triangle \mathrm{OD}>0.204)$. Data were compared with the Kruskal-Wallis test. Abbreviation: $n$, number of samples

whole population (children and adults) between central (Tounouma and Dogona) and peripheral districts (Yeguere and Secteur 25) showed that malaria prevalence was significantly higher in the central districts than in the peripheral ones $(P=0.001)$. Plasmodium falciparum was identified in $98.5 \%(205 / 208)$ and P. malariae in $1.4 \%(3 /$ 208) of all infected individuals in the four districts. The average parasitaemia was 3872 and 275 P. falciparum asexual parasites $/ \mu \mathrm{l}$ of blood in children and adults, respectively (Table 2). Differences in parasitaemia between districts (higher in Tounouma and lower in Secteur 25) were significant only for adults $(P=0.019)$.

\section{IgG against the Anopheles gSG6-P1 salivary peptide}

From all samples $(n=1728)$, a subsample of 273 blood spots was randomly selected to evaluate the exposure to Anopheles bites by assessing the immune response to the salivary gSG6-P1 peptide. The proportion of children and adults tested positive for an IgG response (above the threshold) was 89\% (122/137)

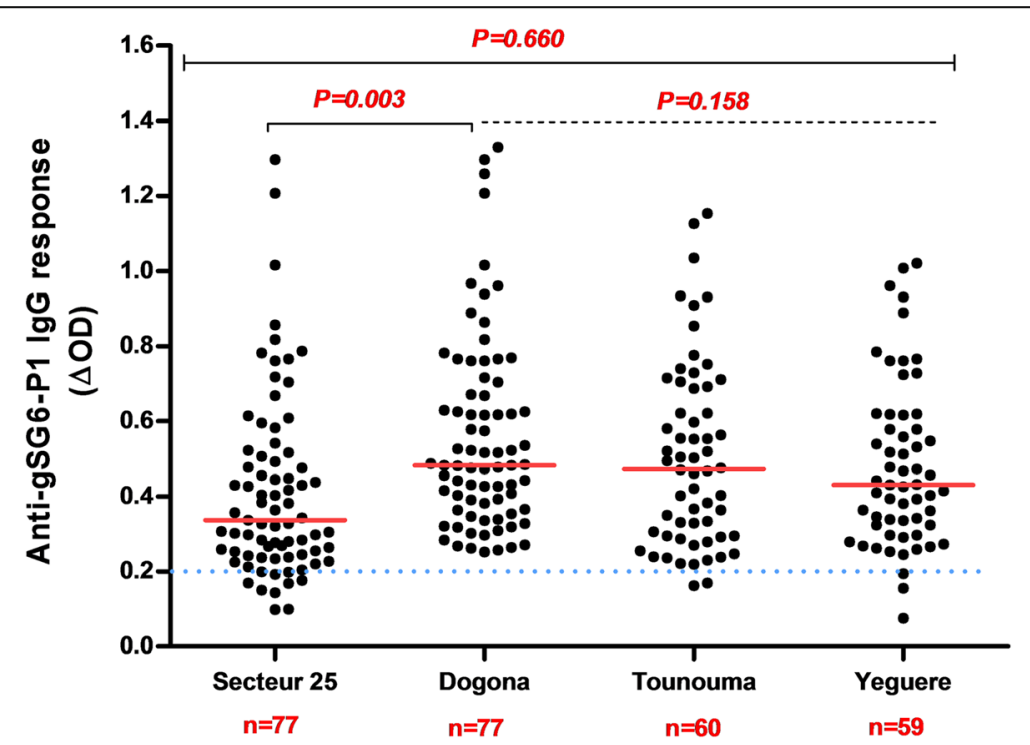

Fig. 3 Anti-gSG6-P1 lgG response according to the district geographic position. Red bars indicate the median value in each group and the horizontal blue dotted line represents the cut-off for immune responders $(\triangle O D>0.204)$. Peripheral districts, Secteur 25 and Yeguere; central districts, Tounouma, Dogona. Data were compared with the Mann-Whitney test. Abbreviation: $n$, number of samples 


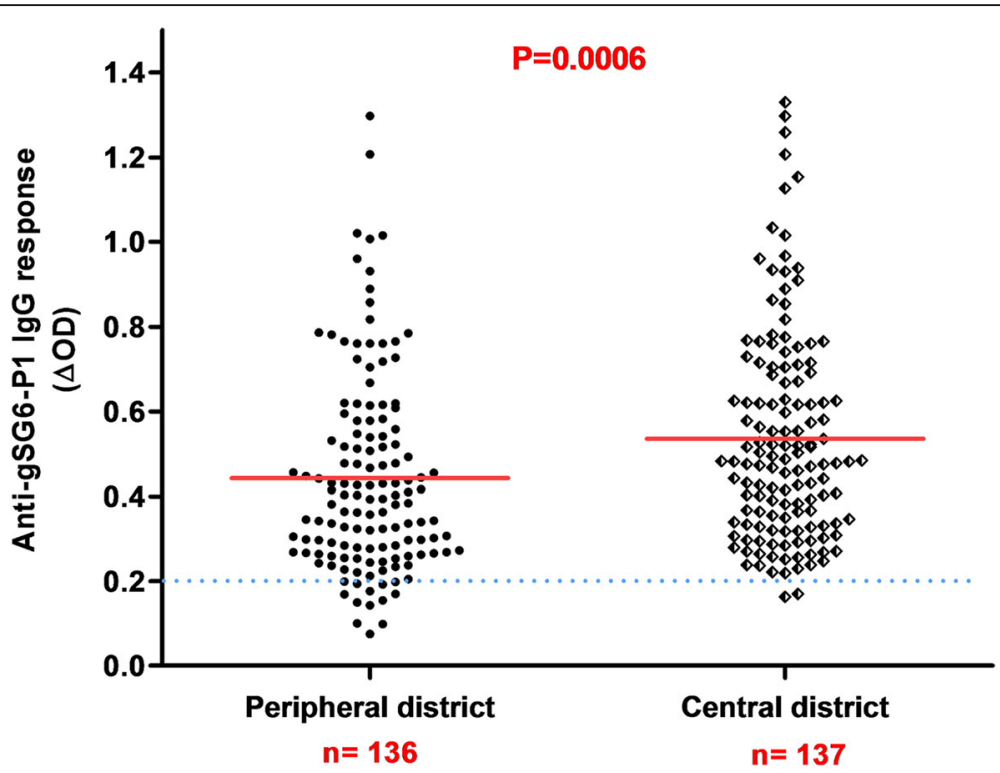

Fig. 4 Anti-gSG6-P1 lgG levels in children and adults according to their malaria infection status. Red bars indicate the median value in each group and the horizontal blue dotted line represents the cut-off for immune responders ( $\triangle O D>0.204)$. Data were compared with the Mann-Whitney test. Abbreviations: Uninf-Adults, non-infected adults; Inf-Adults, infected adults; Uninf-Child, non-infected children; Inf-Child, infected children; n, number of samples

and 99\% (135/137), respectively. No significant difference in the serology analysis based on age was observed among adults (ANOVA: $F_{(4,112)}=1.980, P=0.1023$ ) and children (ANOVA: $\left.F_{(4,115)}=2.365, P=0.0570\right)$. No significant difference was observed between adults and children, (Mann-Whitney U-test: $U=6295, n_{1}=118, n_{2}=120$, $P=0.1396$ ) (Fig. 2). Analysis according to the district showed that the anti-gSG6-P1 IgG levels were significantly lower in Secteur 25 than in Tounouma, Dogona and Yeguere (Mann-Whitney U-test, $U=1781, n_{1}=77$, $\left.n_{2}=77, P=0.0003\right)$ where the anti-gSG6-P1 IgG responses were comparable (Kruskal-Wallis H-test: $X^{2}=3.54, d f=2, P=0.158$ ) (Fig. 3). Analysis according to the district geographical position (central $v s$ peripheral) showed that the anti-gSG6 P1 IgG response was significantly higher in the central than in the peripheral districts (Mann-Whitney test, $U=7072, n_{1}=136$, $n_{2}=137, P=0.0006$ ) (Fig. 4).

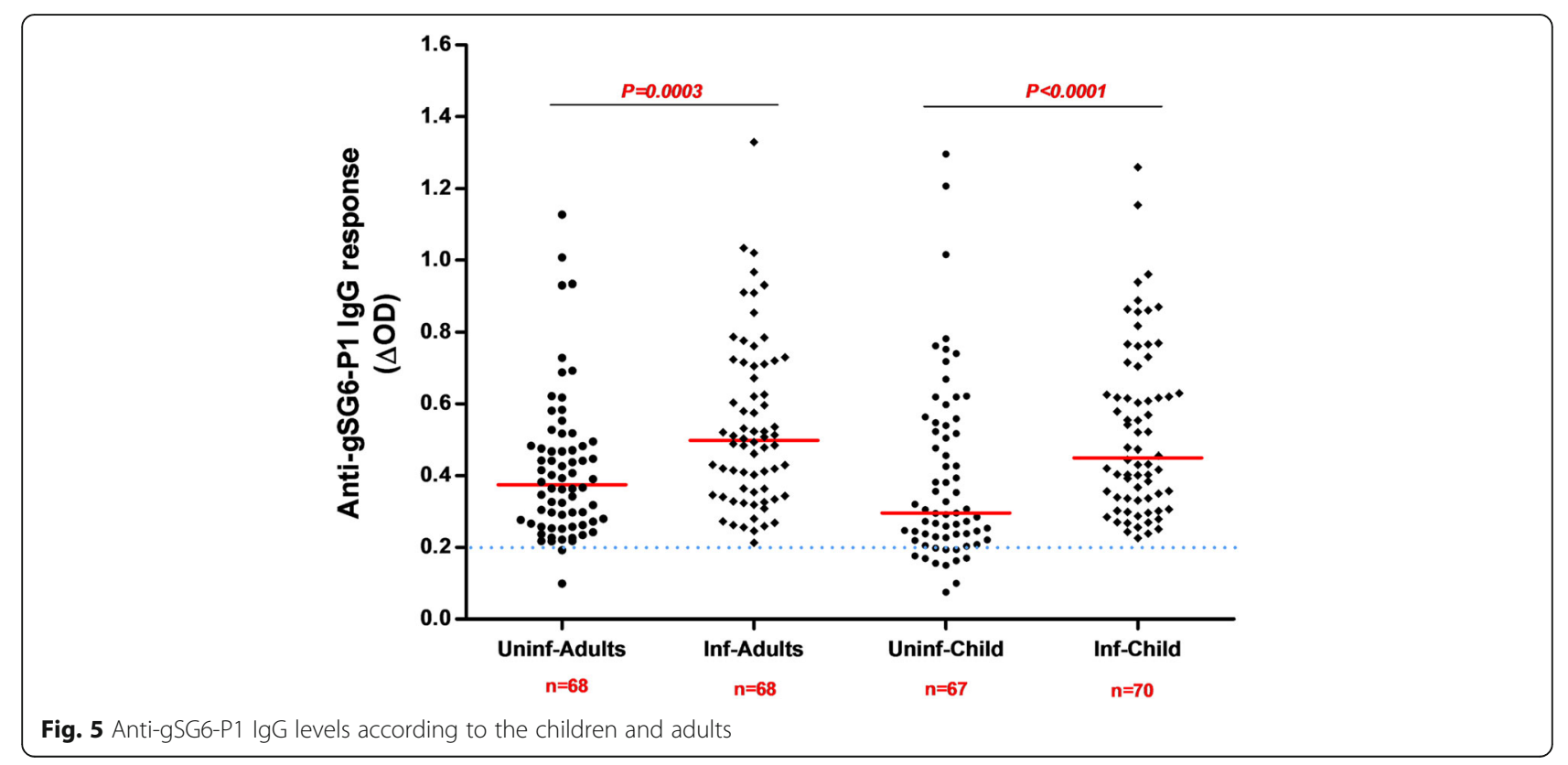


Table 4 Mosquito species collected in the four districts with CDC traps and insecticide spraying

\begin{tabular}{|c|c|c|c|c|c|c|c|c|}
\hline \multirow[t]{2}{*}{ District } & \multicolumn{2}{|c|}{ An. gambiae (s.l.) } & \multicolumn{2}{|c|}{ Aedes spp. } & \multicolumn{2}{|c|}{ Culex spp. } & \multicolumn{2}{|l|}{ Total } \\
\hline & $n$ & $\%$ & $n$ & $\%$ & $n$ & $\%$ & $n$ & $\%$ \\
\hline Yeguere & 11 & 6.0 & 1 & 0.5 & 170 & 93.4 & 182 & 4.4 \\
\hline Secteur 25 & 8 & 7.0 & 2 & 1.8 & 104 & 91.2 & 114 & 2.8 \\
\hline Tounouma & 214 & 7.2 & 2 & 0.1 & 2760 & 92.7 & 2976 & 72.5 \\
\hline Dogona & 45 & 5.4 & 2 & 0.2 & 788 & 94.4 & 835 & 20.3 \\
\hline Total & 278 & 6.8 & 7 & 0.2 & 3822 & 93.1 & 4107 & 100 \\
\hline
\end{tabular}

Abbreviation: $n$, total number of mosquitoes

Analysis according to the infection status (adults and children infected or not by malaria) indicated that the median anti-gSG6-P1 IgG level was significantly higher in infected than non-infected adults (Mann-Whitney U-test: $\left.U=1488, n_{1}=68, n_{2}=68, P=0.0003\right)$ and children (Mann-Whitney U-test, $U=1433, n_{1}=67, n_{2}=70$, $P<0.0001$ ) (Fig. 5).

\section{Entomological patterns of the study sites}

In total, 4107 mosquitoes were caught in the four districts. The population was composed of $93.1 \%$ of Culex spp., 6.8\% of Anopheles spp. and 0.2\% of Aedes spp. (Table 4). The majority of Anopheles specimens were caught in the central districts of Tounouma and Dogona (259/278, 93.2\%). CDC traps provided 72.3\% (201/278) of the Anopheles samples and $86.1 \%$ (173/201) of them were collected with indoor CDC traps. Indoor resting females caught by spraying represented $27.7 \%$ (77/278) of the Anopheles samples.

PCR-based species identification of the An. gambiae (s.l.) females $(n=278)$ was successful for 273 specimens (four specimens from Tounouma and one form Dogona were not identified) (Table 5). The most frequently identified species was $A n$. arabiensis $(83.2 \%, 227 / 273)$, followed by An. coluzzii $(10.6 \%, 29 / 273)$ and An. gambiae (6.2\%, 17/ 273) (Table 3). Anopheles gambiae and An. arabiensis were present in all four districts, but with higher frequencies in the central ones (Tounouma and Dogona). Anopheles arabiensis represented $81.5 \%(185 / 227)$ of catches in Tounouma, whereas An. gambiae was predominant in Dogona (47.1\%, 8/17) (Table 3). Anopheles coluzzii was only found in Tounouma and Dogona.
Moreover, in these 273 Anopheles females, P. falciparum was found only in specimens collected in Tounouma, but not in Yeguere, Secteur 25 and Dogona. In addition, in Tounouma, only An. coluzzii $(5.0 \%, 1 / 20)$ and $A n$. arabiensis $(2.2 \%, 4 / 185)$ were infected by P. falciparum (Table 5).

Analysis of the available blood-fed mosquitoes $(n=100)$ showed that in Tounouma, Dogona and Yeguere, $\geq 25 \%$ had a human blood meal and $\geq 15 \%$ a mixed meal (Table 6). Blood-fed females were not collected in Secteur 25. There was no difference in the blood meal origin distribution in the four districts (KruskalWallis H-test, $\chi^{2}=0.088, d f=2, P=0.9565$ ).

\section{Discussion}

The present study was carried out in four districts of Bobo-Dioulasso to evaluate the spatial disparities in malaria transmission to improve disease control in an urban setting. Despite the significant coverage of mosquito nets, the transmission of malaria occurred in the four districts [21]. Prevalence was higher in the central districts (Tounouma and Dogona) than in the peripheral ones, in relation with the presence of the Houet River. The human population exposure to Anopheles bites was confirmed by assessing the specific IgG response to the gSG6-P1 salivary peptide. Exposure was also higher in Tounouma and Dogona. Moreover, parasitaemia in children was higher in Bobo-Dioulasso compared to what was observed in Ouagadougou in 2004. The mean of the parasitaemia among positive children was 602 P. falciparum asexual parasites/ $\mu \mathrm{l}$ of blood (95\% CI: 545-665) [22]. Furthermore, prevalence was higher than the value reported

Table $\mathbf{5}$ Identification of malaria vector species in the four districts

\begin{tabular}{|c|c|c|c|c|c|c|c|c|c|c|c|c|}
\hline \multirow[t]{2}{*}{ District } & \multicolumn{3}{|c|}{ An. gambiae } & \multicolumn{3}{|c|}{ An. coluzzii } & \multicolumn{3}{|c|}{ An. arabiensis } & \multicolumn{3}{|c|}{ Total } \\
\hline & $n$ & $\%$ & Positive for P.f & $n$ & $\%$ & Positive for P.f & $n$ & $\%$ & Positive for P.f & $n$ & $\%$ & Positive for P.f \\
\hline Yeguere & 1 & 9.1 & 0 & 0 & 0.0 & 0 & 10 & 90.9 & 0 & 11 & 4.0 & 0 \\
\hline Secteur 25 & 3 & 37.5 & 0 & 0 & 0.0 & 0 & 5 & 62.5 & 0 & 8 & 2.9 & 0 \\
\hline Tounouma & 5 & 2.4 & 0 & 20 & 9.5 & 1 & 185 & 88.1 & 4 & 210 & 76.9 & 5 \\
\hline Dogona & 8 & 18.2 & 0 & 9 & 20.5 & 0 & 27 & 61.4 & 0 & 44 & 16.1 & 0 \\
\hline Total & 17 & 6.2 & 0 & 29 & 10.6 & 1 & 227 & 83.2 & 4 & 273 & 100 & 5 \\
\hline
\end{tabular}

Abbreviations: $n$, total number of individuals per species (four specimens were not identified in Tounouma and one in Dogona); P.f, Plasmodium falciparum 
Table 6 Blood meal origin according to the district

\begin{tabular}{|c|c|c|c|c|c|c|c|c|c|c|c|c|}
\hline \multirow[t]{2}{*}{ District } & \multicolumn{7}{|c|}{ Animals } & \multicolumn{2}{|c|}{ Human } & \multicolumn{2}{|c|}{ Mixed } & \multirow{2}{*}{$\begin{array}{l}\text { Total } \\
n\end{array}$} \\
\hline & Cattle & Sheep & Donkey & Pig & Dog & Other & $\%$ & $n$ & $\%$ & $n$ & $\%$ & \\
\hline Yeguere & 3 & 0 & 2 & 0 & 1 & 0 & 54.5 & 3 & 27.3 & 2 & 18.2 & 11 \\
\hline Secteur 25 & 0 & 0 & 0 & 0 & 0 & 0 & 0 & 0 & 0 & 0 & 0 & 0 \\
\hline Tounouma & 9 & 6 & 9 & 2 & 0 & 1 & 55.1 & 14 & 28.6 & 8 & 16.3 & 49 \\
\hline Dogona & 1 & 9 & 7 & 3 & 3 & 1 & 60.0 & 10 & 25.0 & 6 & 15.0 & 40 \\
\hline Total & 13 & 15 & 18 & 5 & 4 & 2 & 57.0 & 27 & 27.0 & 16 & 16.0 & 100 \\
\hline
\end{tabular}

Abbreviations: $n$, number of blood-fed Anopheles females; Other, other animals not determined; Mixed, animal and human meal

by Yaméogo et al. [23] in 2012 for Bobo-Dioulasso that was $14.05 \%$. This result could be explained by inadequate mosquito net use. Although people declared they slept under their bednet the night before the survey, we did not control this by house visiting at night or early in the morning. This can be considered as a limitation of the study. Recently, Taylor et al. [24] showed that ownership of mosquito nets increased in Burkina Faso from 6\% in 2003 to $57 \%$ in 2010. Similarly, in Niger, ownership increased to $65.1 \%$ in all households and to $74.6 \%$ in households with children under 5 ; however, the authors found that only $33 \%$ of people had slept under their mosquito net the night before the survey [25]. On the other hand, a robust use of mosquito control tools (long lasting insecticide impregnated nets, mosquito coils, insecticide sprays) could lead to a change in the vector biting behaviour. This was observed in Benin, where $26.4 \%$ of all An. funestus specimens was caught after 06:00 h [26]. Thus, in BoboDioulasso, transmission could also occur early in the morning when people leave their mosquito net. At the end, An. arabiensis was the main vector in BoboDioulasso as previously reported by Dabiré et al. [13, 27].
The presence of An. arabiensis could also help understanding the persistence of malaria transmission. Indeed, its exophilic behaviour could reduce the effectiveness of vector control interventions that specifically target endophilic species, thus allowing residual transmission outside houses.

The higher malaria risk in central areas of BoboDioulasso was relatively unexpected. Indeed, in BurkinaFaso, the risk of malaria is generally considered to be more elevated in suburban than central areas because of the persistency of rural features that favour the presence of malaria vectors [22]. The opposite situation in BoboDioulasso could be linked to the specific environmental situation, characterized by an important hydrographic network within the town and urban agricultural activities that provide breeding sites for malaria vectors even if the river is polluted (organic pollutants or heavy metals and oil) [13, 28] (Fig. 5). Although larval prospections were not conducted in our study which can be considered as a limitation, presence of larvae in the Houet river was previously observed [13]. The presence of Anopheles larvae in polluted water was previously

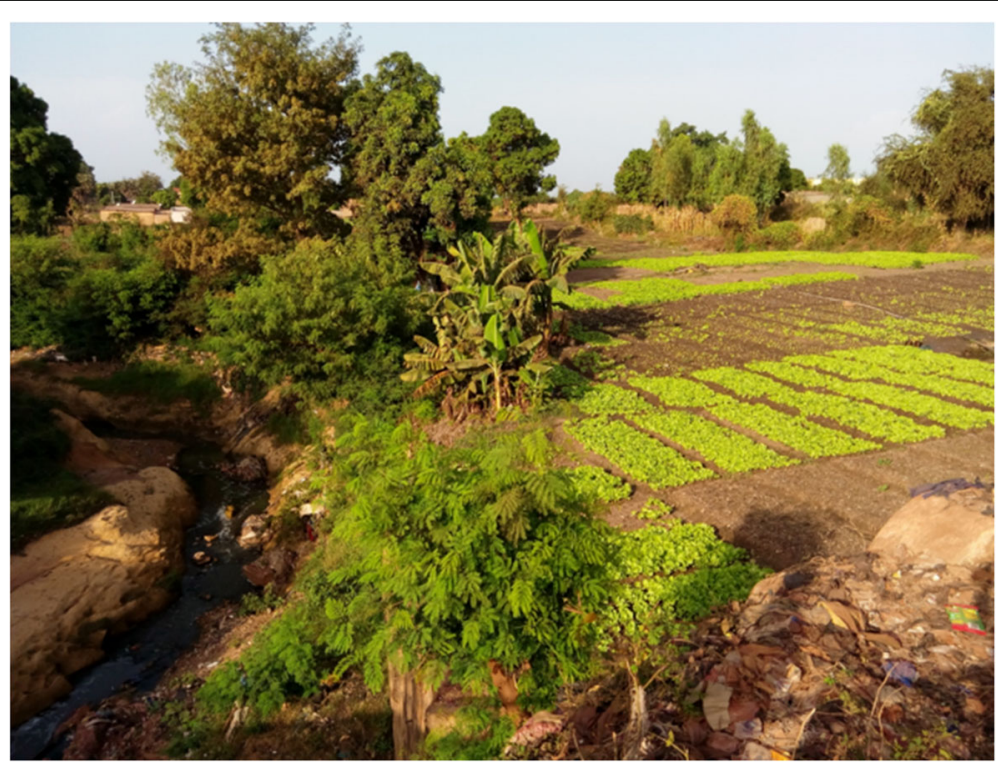

Fig. 6 Urban agricultural activities in the central district of Dogona 
reported in Dakar, Accra, Dar es Salaam, and Lagos [6, 29-31]. In agreement, in Secteur 25 where the gSG6P1 IgG response and malaria prevalence were the lowest, $69.3 \%$ of households were located more than $500 \mathrm{~m}$ from the hydrographic network. Conversely, in Tounouma and Dogona where the gSG6-P1 IgG responses and malaria prevalence were the highest, 73.1 and $63.8 \%$ of the households, respectively, were less than $200 \mathrm{~m}$ from the hydrographic network. Similar results were previously reported [15-17, 32].

\section{Conclusions}

The transmission of malaria was investigated in four districts of Bobo-Dioulasso that were selected to illustrate the great ecological diversity of the urban environment. District disparities in malaria prevalence were observed in children, highlighting that they were particularly exposed to malaria in the central part of the town. Environmental factors, such as urban agricultural activities along the Houet River favor the presence of malaria vectors and then hostvector contact (Fig. 6). Moreover, the major vector, $A n$. arabiensis, is an exophilic species against which mosquito nets are less efficient. If sociological factors, such as a good education level, can strongly influence malaria impact within a population, environmental factors may be improved by better urban planning and management, calling for awareness to build sustainable healthy cities.

\section{Abbreviations \\ Ab: Antibody; ELISA: Enzyme-linked immunosorbent assay; Ig: Immunoglobulin; LLIN: Long-lasting insecticide impregnated nets; mRDT: Malaria rapid diagnostic test; OD: Optical density; PBS: Phosphate-buffered saline; PCR: Polymerase chain reaction; PNLP: Programme National de Lutte Contre le Paludisme (National Malaria Control Programme; WHO: World Health Organization}

\section{Acknowledgements}

The authors are grateful to the population in Bobo-Dioulasso for their warm acceptance and to the team of interviewers and other field workers for their great support. The authors thank Dr Emmanuel Elanga-Ndille for training in ELISA salivary biomarker. They are grateful to Dr André Sagna for reviewing the first version of the manuscript and contributing to improve it. We would like to thank also Dr Yerbanga from IRSS and the technicians, Mr Traoré, Mr Sankara and Mr Tamboula who read the blood smears and those at Centre Muraz who prepared, computerized, and verified the data, particularly Mr Diallo. We are grateful to Mr Meda and Mr Somda for his technical assistance on ELISA analysis.

\section{Funding}

Core funding was provided by the Agence Nationale de la Recherche (ANR12-INEG-007). The Centre National de la Recherche Scientifique (CNRS), France, had also supported the study by a grant (PEPS "ecological inequities") which allowed the team to provide remote sensing data from the Centre National des Etudes Spatiales (CNES), France, for the spatial sampling strategy. DK was supported by a fellowship program from the Institut de Recherche pour le Développement.

\section{Availability of data and materials}

The data supporting the conclusions of this article are included within the article. The datasets used during the current study available from the corresponding author upon reasonable request.

\section{Authors' contributions}

GS was the principal investigator of the SANTINELLES Project. FF was the principal scientific investigator of the study in Bobo-Dioulasso. She participated in the study design, coordinated the field and laboratory work in Burkina Faso with KRD for the malaria part of the project. KRD and FF coordinated the manuscript draft. DK coordinated the geographical part of the study, was responsible of sampling strategy, and participated in the field work with SS, FK and AO. DDS carried out laboratory and statistical analysis, interpretation of the ELISA data, drafted and revised the manuscript. WM and GAO provided technical input to the analysis and revisions of the manuscript. All authors read and approved the final manuscript.

Ethics approval and consent to participate

The protocol was approved by the institutional ethics committee of Centre Muraz (statement No. A30-2013 to 09/19/2013). The procedures of the study were fully explained to participants and written informed consent was obtained for individuals and child parents included in the study.

\section{Competing interests}

The authors declare that they have no competing interests.

\section{Publisher's Note}

Springer Nature remains neutral with regard to jurisdictional claims in published maps and institutional affiliations.

\section{Author details}

${ }^{1}$ Institut de Recherche en Sciences de la Santé/Centre Muraz, Bobo-Dioulasso BP 545, Burkina Faso. ${ }^{2}$ Université Nazi Boni, Bobo-Dioulasso BP 109, Burkina Faso. ${ }^{3}$ Université Paris Ouest Nanterre La Défense, 200 Avenue de la République, 92000 Nanterre, France. ${ }^{4}$ UMR MIVEGEC (IRD, CNRS, UM), Institut de Recherche pour le Développement, 911, Avenue Agropolis, BP 64501, 34394 Montpellier Cedex 5, France. ${ }^{5}$ UMR ASTRE, CIRAD, CIRAD TA C-22/E, Campus International de Baillarguet, 34398 Montpellier Cedex 5, France. ${ }^{6}$ Insect Pest Control Laboratory, Joint FAO/IAEA Division of Nuclear Techniques in Food and Agriculture, Vienna, Austria. Institut de Recherche Agricole pour le Développement (IRAD), Yaoundé, Cameroon. ${ }^{8} \mathrm{CEPED}$, Institut de Recherche pour le Développement, 45 rue des Saints-Pères, 75006 Paris, France.

Received: 31 December 2017 Accepted: 18 April 2018

Published online: 11 May 2018

\section{References}

1. WHO. World malaria report 2017. 2017. http://www.who.int/malaria/ publications/world-malaria-report-2017. Accessed 08 Dec 2017.

2. UN Habitat. Time to think urban: UN-Habitat brochure. 2013. https:// unhabitat.org/time-to-think-urban-un-habitat-brochure-2013/. Accessed 14 Mar 2014

3. Tatem AJ, Gething PW, Smith DL, Hay SI. Urbanization and the global malaria recession. Malar J. 2013;12:133.

4. Trape JF, Pison G, Spiegel A, Enel C, Rogier C. Combating malaria in Africa. Trends Parasitol. 2002:18:224-30.

5. Dossou-Yovo J, Doannio JM, Diarrassouba S, Chauvancy G. The impact of rice fields on malaria transmission in the city of Bouake, Cote d'Ivoire. Bull Soc Pathol Exot. 1998:91:327-33. (In French)

6. Machault V, Gadiaga L, Vignolles C, Jarjaval F, Bouzid S, Sokhna C, et al. Highly focused anopheline breeding sites and malaria transmission in Dakar. Malar J. 2009;8:138.

7. Rakotomanana F, Ratovonjato J, Randremanana RV, Randrianasolo L, Raherinjafy R, Rudant J, et al. Geographical and environmental approaches to urban malaria in Antananarivo (Madagascar). BMC Infect Dis. 2010;10:173.

8. Carlson JC, Byrd BD, Omlin FX. Field assessments in western Kenya link malaria vectors to environmentally disturbed habitats during the dry season. BMC Public Health. 2004;7:1-7.

9. Fournet F, Cussac M, Ouari A, Meyer P-E, Toé HK, Gouagna L-C, et al. Diversity in anopheline larval habitats and adult composition during the dry and wet seasons in Ouagadougou (Burkina Faso). Malar J. 2010;9:78.

10. UN Habitat. Unmasking and ovrcoming health inequities in urban settings: UN-Habitat Hides Cities. 2010. http://www.who.int/kobe-centre/publications/ hidden-cities:Unmasking and ovrcoming health inequities in urban settings2010/. Accessed 17 Nov 2010. 
11. Institut National de la Statistique et de la Démographie (INSD). Annuaire statistique 2015. 2016.

12. Robert V, Gazin P, Ouedraogo V, Carnevale P. Le paludisme urbain a BoboDioulasso (Burkina Faso). Cah ORSTOM. 1986;24:121-8.

13. Dabiré RK, Namountougou M, Sawadogo SP, Yaro LB, Toé HK, Ouari A, et al. Population dynamics of Anopheles gambiae s.l. in Bobo-Dioulasso city: bionomics, infection rate and susceptibility to insecticides. Parasit Vectors. 2012;5:127.

14. Kassié D, Roudot A, Dessay N, Piermay JL, Salem G, Fournet F. Development of a spatial sampling protocol using GIS to measure health disparities in Bobo-Dioulasso, Burkina Faso, a medium-sized African city. Int J Health Geogr. 2017;16:1-16.

15. Poinsignon A, Cornelie S, Mestres-Simon M, Lanfrancotti A, Rossignol M, Boulanger D, et al. Novel peptide marker corresponding to salivary protein gSG6 potentially identifies exposure to Anopheles bites. PLoS One. 2008;3:6.

16. Drame PM, Machault V, Diallo A, Cornelie S, Poinsignon A, Lalou R, et al. IgG responses to the gSG6-P1 salivary peptide for evaluating human exposure to Anopheles bites in urban areas of Dakar region, Sénégal. Malar J. 2012;11:72.

17. Sagna AB, Sarr JB, Gaayeb L, Drame PM, Ndiath MO, Senghor S, et al. gSG6P1 salivary biomarker discriminates micro-geographical heterogeneity of human exposure to Anopheles bites in low and seasonal malaria areas. Parasit Vectors. 2013:6:68

18. Santolamazza F, Mancini E, Simard F, Qi Y, Tu Z, della Torre A. Insertion polymorphisms of SINE200 retrotransposons within speciation islands of Anopheles gambiae molecular forms. Malar J. 2008;7:163.

19. Morlais I, Ponçon N, Simard F, Cohuet A, Fontenille D. Intraspecific nucleotide variation in Anopheles gambiae: New insights into the biology of malaria vectors. Am J Trop Med. Hyg. 2004;71:795-802.

20. Beier JC, Perkins PV, Wirtz RA, Koros J, Diggs D, Gargan T, et al. Blood meal identification by direct enzyme-linked immunosorbent assay (ELISA), tested on Anopheles (Diptera: Culicidae) in Kenya. J Med Entomol. 1988;25:9-16.

21. PNLP/Burkina Faso. Directives nationales pour la prise en charge du paludisme dans les formations sanitaires du Burkina Faso. Ministère de la Santé/Burkina Faso; 2014

22. Baragatti M, Fournet F, Henry M, Assi S, Ouedraogo H, Rogier C, et al. Social and environmental malaria risk factors in urban areas of Ouagadougou, Burkina Faso. Malar J. 2009:14:13.

23. Yameogo TM, Tapsoba SP, Sombie I, Guiguemde TR. Evaluation of application of national guidelines for the management of malaria in BoboDioulasso university hospital. Sante Publique. 2015;27:265-73. (In French)

24. Taylor C, Ye Y, Taylor C. Equity trends in ownership of insecticide-treated nets in 19 sub-Saharan African countries. Bull World Health Organ. 2017;95: 322-32.

25. Thwing J, Hochberg N, Eng J, Vanden IS, Eliades MJ, Minkoulou E, et al. Insecticide-treated net ownership and usage in Niger after a nationwide integrated campaign. Trop Med Health. 2008;13:827-34.

26. Moiroux N, Gomez MB, Pennetier C, Elanga E, Djènontin A, Chandre F, et al. Changes in Anopheles funestus biting behavior following universal coverage of long-lasting insecticidal nets in Benin. J Infect Dis. 2012;206:1622-9.

27. Dabiré KR, Sawadogo PS, Hien DF, Bimbilé-Somda NS, Soma DD, Millogo A, et al. Occurrence of natural Anopheles arabiensis swarms in an urban area of Bobo-Dioulasso city, Burkina Faso, West Africa. Acta Trop. 2014;130:44-50.

28. Fournet F, Kassié D, Dabiré RK. Analyse de la distribution socio-spatiale du paludisme dans une ville moyenne ouest africaine, Bobo-Dioulasso (Burkina Faso). Dynamiques Environnementales Int. des géosciences l'environnement. 2015;2:155-69.

29. Chinery WA. Effects of ecological changes on the malaria vectors Anopheles funestus and the Anopheles gambiae complex of mosquitoes in Accra, Ghana. J Trop Med Hyg. 1984;87:75-81.

30. Sattler MA, Mtasiwa D, Kiama M, Premji Z, Tanner M, Killeen GF, et al. Habitat characterization and spatial distribution of Anopheles sp. mosquito larvae in Dar es Salaam (Tanzania) during an extended dry period. Malar J. 2005:4:4.

31. Awolola TS, Oduola AO, Obansa JB, Chukwurar NJ, Unyimadu JP. Anopheles gambiae s.s. breeding in polluted water bodies in urban Lagos, southwestern Nigeria. J Vector Borne Dis. 2007:44:241-4.

32. Poinsignon A, Cornelie $S, B a F$, Boulanger $D$, Sow $C$, Rossignol $M$, et al. Human IgG response to a salivary peptide, gSG6-P1, as a new immunoepidemiological tool for evaluating low-level exposure to Anopheles bites. Malar J. 2009;8:198.

\section{Ready to submit your research? Choose BMC and benefit from:}

- fast, convenient online submission

- thorough peer review by experienced researchers in your field

- rapid publication on acceptance

- support for research data, including large and complex data types

- gold Open Access which fosters wider collaboration and increased citations

- maximum visibility for your research: over $100 \mathrm{M}$ website views per year

At BMC, research is always in progress.

Learn more biomedcentral.com/submissions 